\title{
Nanopesticides and Nanofertilizers and Agricultural Development: Scopes, Advances and Applications
}

\author{
Amra Bratovcic ${ }^{*}$, Wafaa M. Hikal ${ }^{2,3^{*}}$, Hussein A. H. Said-Al Ahl ${ }^{4}$, Kirill G. Tkachenko ${ }^{5}$ \\ Rowida S. Baeshen², Ali S. Sabra4, Hoda Sany ${ }^{6}$ \\ ${ }^{1}$ Department of Physical Chemistry and Electrochemistry, Faculty of Technology, University of Tuzla, Tuzla, \\ Bosnia and Herzegovina \\ ${ }^{2}$ Department of Biology, Faculty of Science, University of Tabuk, Tabuk, Saudi Arabia \\ ${ }^{3}$ Water Pollution Research Department, Environmental Research Division, National Research Centre, \\ Dokki, Giza, Egypt \\ ${ }^{4}$ Medicinal and Aromatic Plants Research Department, National Research Centre, Dokki, Giza, Egypt \\ ${ }^{5} \mathrm{~V}$. L. Komarov Botanical Institute of the Russian Academy of Sciences, Saint Petersburg, Russia \\ ${ }^{6}$ Department of Botany (Plant Physiology Section), Faculty of Agriculture, Cairo University, Giza, Egypt \\ Email: *amra.bratovcic@untz.ba, *wafaahikal@gmail.com
}

How to cite this paper: Bratovcic, A. Hikal, W.M., Said-Al Ahl, H.A.H., Tkachenko, K.G., Baeshen, R.S., Sabra, A.S. and Sany, H. (2021) Nanopesticides and Nanofertilizers and Agricultural Development: Scopes, Advances and Applications. Open Journal of Ecology, 11, 301-316. https://doi.org/10.4236/oje.2021.114022

Received: February 23, 2021

Accepted: March 20, 2021

Published: March 23, 2021

Copyright $\odot 2021$ by author(s) and Scientific Research Publishing Inc. This work is licensed under the Creative Commons Attribution International License (CC BY 4.0).

http://creativecommons.org/licenses/by/4.0/

\begin{abstract}
Excessive use of pesticides and fertilizers in agriculture in order to increase yields has proved unnecessary because a large part of them remain unused and have negative effects on the environment and human health. Therefore, it is a great challenge for farmers to replace the application of pesticides and fertilizers with nanopesticides and nanofertilizers, with the aim of reducing the use of mineral fertilizers and increasing yields, as well as supporting agricultural development. This review provides a detailed overview of the classification of pesticides, commonly used nanoparticles in agriculture and their function, as well as impact of nanopesticides and nanofertilizers on the environment. The application of nanopesticides and nanofertilizers and new delivery mechanisms to improve crop productivity are reviewed and described. Particularly, the advantage of the nanoencapsulation process is emphasized for both pesticides and fertilizers. For hydrophobic pesticides, it may be a tool to provide greater stability, dispersion in aqueous media, and allowing a controlled release of the active compound, which increases its effectiveness. In nanofertilizers, micro- or macronutrients can be encapsulated by nanomaterials which allow to release of nutrients into the soil gradually and in a controlled way maintaining soil fertility, thus preventing eutrophication and pollution of water resources. Risks assessment of application of nanopesticides and nanofertilizers in agriculture are required for their correct and safe application.
\end{abstract}




\section{Keywords}

Nanotechnology, Agriculture, Nanopesticides, Nanofertilizers

\section{Introduction}

Nanotechnology is rapidly developing technology impacts every aspect of the food system from cultivation to food production to processing, packaging, transportation, shelf life, and bioavailability of nutrients [1]. Nanotechnology is an interdisciplinary promising research field in developing new tools for plant disease treatments, pathogen detection, and improving the ability of plants to absorb nutrients [2] [3]. Besides this, nanotechnology takes place in the production of nanofertilizers for increasing the efficacy and bioavailability of such new fertilizers as well as decreasing the loss of these materials to the surrounding environment [4]. The application of nanotechnology in the agri-food sector is one of the fastest-growing fields in nano-research. The application of nanoagrochemicals seems crucial for promoting the modern type of agriculture. Application of nanotechnology include: 1) nanoformulations of agrochemicals for applying pesticides and fertilizers for crop improvement; 2) the application of nanosensors/nanobiosensors in crop protection for the identification of diseases and residues of agrochemicals; 3) nanodevices for the genetic manipulation of plants; 4) plant disease diagnostics; 5) animal health, animal breeding, poultry production; and 6) postharvest management [5].

Biological naturally occurring nanoparticles (nanoclay, tomato carotenoid lycopene, many chemicals derived from soil organic matter, lipoproteins, exosomes, magnetosomes, viruses, ferritin) have diverse structures with wide-ranging biological roles. Biological nanoparticles are often biocompatible and have reproducible structures [6].

Nanoscale carriers can be utilized for the efficient delivery of fertilizers, pesticides, herbicides, and plant growth regulators. They can anchor the plant roots to the surrounding soil structure and organic matter thus reducing chemical runoff and alleviating environmental problems. These will help in increasing the bioavailability of active ingredients to the plant, thereby reducing the amount of effort and waste product [7].

It was observed that $\mathrm{SiO}_{2}$ nanoparticles enhanced germination in tomato ( $\mathrm{LY}$ copersicum esculentum) seeds [8].

A variety of nanomaterials like nanopesticides, nanoinsecticide, nanoemulsions, and nanoparticles were developed using nanotechnology. Nanomaterials provide a platform to deliver agrochemicals and various macromolecules needed for plant growth enhancement and resistance to stresses. Smart delivery of agrochemicals increases the yield by optimizing water and nutrient conditions [9].

The global nanopesticide market size is expected to grow at a significant CAGR 
of $14.6 \%$ during the forecast period 2020 to 2027. The increasing demand for food production globally and the rising use of various pesticides around the globe are some major factors to drive the market growth over the forecast period. The global nanopesticide market is segmented into product type, application, end-user, and region. On the basis of type, the market is classified into insecticides, herbicides, fungicides, and nematicides. The insecticides segment held the largest market share in 2019 and accounted for over $41 \%$ of market share in terms of revenue Research Corridor (2020) [10].

The number of publications for the term "nanopesticides" and "nanofertilizers" on Science Direct clearly shows that scientists started intensive research only 5 years ago. Figure 1 shows the graphical number of publications in the last ten years for these terms.

\section{Nanopesticides}

Pesticides are commonly used in agriculture to improve crop yield and efficiency. Urea is the most-widely used fertilizer for crop production and source of nitrate, nitrite, and urease that are ubiquitous contaminants in water causing eutrophication posing environmental implications [11] [12]. According to global urea market report, the demand for urea is 187.8 million metric tons in 2020 ,

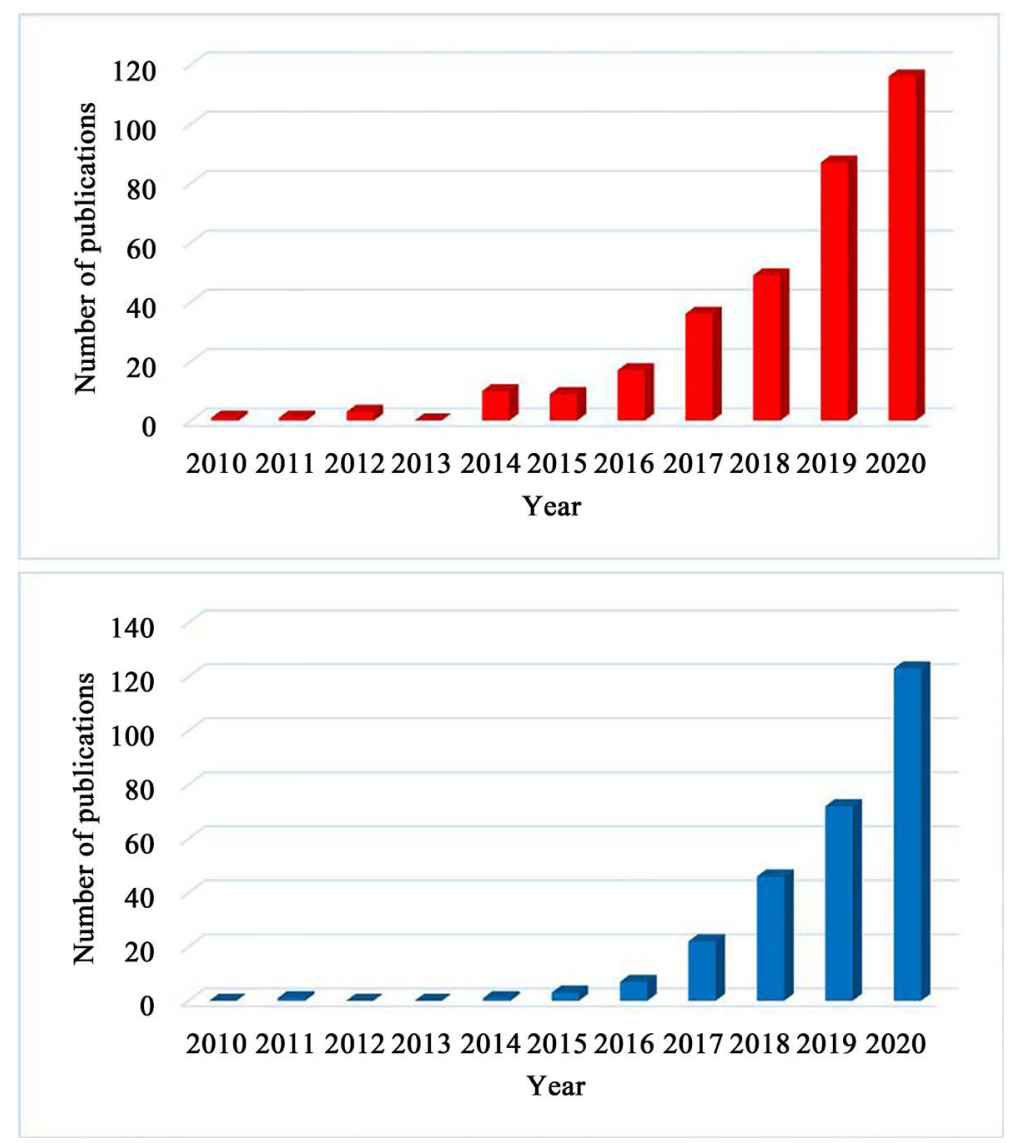

Figure 1. The graphical number of publications on Science Direct in the last ten years for "nanopesticides" and "nanofertilizers". 
and it is estimated that by 2026 that demand will be 211.5 million metric tons.

Figure 2 illustrates the classification of pesticides. Among pesticides, organo-phosphates, neonicotinoids, carbamates and atrazines are some of the dominant classes and their residues even at low concentration persist longer in soil due to low homogeneity. Pesticides can be classified based on their intended target organism as insecticides, herbicides, fungicides, nematicides, rodenticides, and miticides. Also, according to their intended use, they are divided as defoliants, desiccants, fumigants, and plant growth regulators [13].

Nanopesticides offer a way to both control delivery of pesticides and achieve greater effects with a lower chemical dose. The first type of nanopesticides can be foreseen in the form of active ingredient(s) that are either manufactured nanomaterials such as metal nanoparticles (e.g. silver and copper) [14] [15] or metal oxide nanoparticles (e.g. zinc oxide, copper oxide, manganese dioxide, silicon dioxide, titanium dioxide) [16] [17] [18]. The synthesis and application of nanopesticides aimsto enhance efficacy and durability of a pesticide and at the same time to reduce the amount of active ingredients present and minimize or eliminate any potential hazards. Figure 3 illustrates commonly used nanoparticles
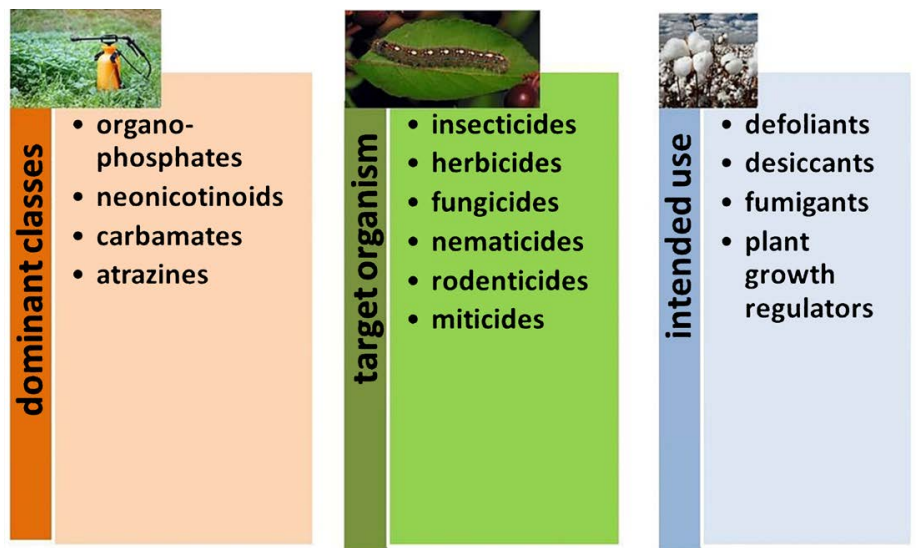

Figure 2. Classification of pesticides.

\begin{tabular}{|c|c|}
\hline \multicolumn{2}{|c|}{ Commonly used nanoparticles in agriculture } \\
\hline Polymeric nanoparticles & $\begin{array}{l}\text { - delivery of agrochemicals } \\
\text { - superior biocompatibility } \\
\text { - minimal impact on non- } \\
\text { targeted organisms. }\end{array}$ \\
\hline Silver nanoparticles & $\begin{array}{l}\text { - antimicrobial property } \\
\text { - enhance plant growth. }\end{array}$ \\
\hline Nano alumino-silicates & - an efficient pesticide \\
\hline $\begin{array}{l}\text { Titanium dioxide } \\
\text { nanoparticles }\end{array}$ & - disinfecting agent for water \\
\hline Carbon nanomaterials & $\begin{array}{l}\text { as graphene, graphene oxide, } \\
\text { carbon dots, and fullerenes, } \\
\text { are used for improved seed } \\
\text { germination. }\end{array}$ \\
\hline
\end{tabular}

Figure 3. Commonly used nanoparticles in agriculture. 
in agriculture and their function.

Many nanoemulsions have been formulated with the application of herbicides and pesticides. Some of the major potential advantages of pesticide nanoemulsions over other methods include their strong adhesion to surfaces, high penetrability, and broad range of applicability [19].

In nanotechnology, the process of encapsulation is frequently used and it implies a process of entrapping one substance within another substance producing particles with diameters of a few $\mathrm{nm}$ to a few $\mathrm{mm}$. The main reason for using encapsulation is the fact that some nutrients do not remain in the soil for a significant amount of time or may react with the other soil components causing undesirable effects [20].

The nanoencapsulation process is used for both pesticides and fertilizers. Nanoencapsulation is also used for pesticides, especially for hydrophobic, (their insolubility in water is a limiting factor); this tool provides greater stability, improving its dispersion in aqueous media, and allowing a controlled release of the active compound, which increases its effectiveness in the control of pests and reduces the doses of treatment in crops and human exposure [21] [22] [23].

The polymers used in nano-encapsulation for nanopesticides are generally of natural origin, such as polysaccharides (e.g. alginate, carrageenan, xanthan gum, chitosan, modified starch), and proteins (chicken egg albumin, zein, casein, $\alpha$-lactalbumin, $\beta$-lactoglobulin, collagen, gelatine) [24] [25]. Coacervates of proteins and negatively charged polysaccharides have also been used for the nanoencapsulation ofvarious substances.

Clay nanotubes (halloysite) have been developed as carriers of pesticides for low cost, extended-release and better contact with plants, and they might reduce the amount of pesticides by $70 \%-80 \%$, thus reducing the cost of pesticide and also the impact on water streams [26].

Polylactide nanocomposites are characterized with high sorption capacity and enhanced conductivity properties (up to 6 or even 9 orders of magnitude) with respect to the pristine polymer (Conductivity $=1 \times 10^{-10} \mathrm{~S} / \mathrm{m}$ ) [27]. These properties of nanocomposites can be applicable in the plant-soil-water interface to increase the ion transport and sorption of nutrients.

Residues of products of nanopesticides containing nano-sized or nano-formulated agro-chemicals might be present in products as consumed [28]. Moreover, the slow release of the active components in pesticides through nanocapsules or nanoemulsions implies a greater persistence in the organism and as a result, a greater risk [29].

In a study carried out by Gao et al. [30], an adhesive hollow mesoporous silica hybrid with a well-defined spherical shape was used as a nanocarrier of cyantraniliprole (CNAP) to fabricate an adhesive nanopesticide (CNAP-HMS-PDAAM). The results indicated that CNAP-HMS-PDAAM showed long-term control efficacies against Cnaphalocrocis medinalis (Guenee) and Chilo suppressalis (Walker), mainly due to its strong adhesive property on rice leaves and its sustained 
release properties. Twenty-eight days after spraying, the efficacy of all four doses of CNAP-HMS-PDAAM was significantly better than that of Benevia (cyantraniliprole $10 \%$ EOD). In addition, the nanocarriers showed good biocompatibility and had no obvious influence on the growth of rice.

Copper-based (nano) pesticides in agroecosystems may result in unintended consequences on non-target soil microbial communities, due to their antimicrobial broad spectrum. Peixoto et al. [31] studied the impact of a commercial $\mathrm{Cu}(\mathrm{OH})_{2}$-nanopesticide, over 90 days, at single and season agricultural application doses, in the presence and absence of an edaphic organism (the isopod Porcellionides pruinosus), on microbial communities' function, structure and abundance. The nanopesticide application resulted in significant changes on both bacterial and fungal communities'structure, particularly at the season application. At the functional level, a significant increase in microbial ability of carbon utilization and a significant decrease in the $\beta$-glucosidase activity were observed for communities exposed to the nanopesticide. This study revealed that $\mathrm{Cu}(\mathrm{OH})_{2}$-nanopesticideimpact the soil microbial community, possibly affecting its ecological role.

Nowadays, scientists are giving their attention to the application of silica nanomaterials in agriculture. Nanosilica-based fertilizers/pesticides/herbicides can improve the growth and yield of crops. Silica nanoparticles can be easily inserted into plants. It may modify the plant's catabolism and anabolism [32].

\section{Nanofertilizers}

Nanofertilizer technology is very innovative. Micro-or macronutrients in nanofertilizers can be encapsulated by nanomaterials, coated with a thin protective film, or delivered as emulsions or nanoparticles [33]. The application of nanofertilizers allows to release of nutrients into the soil gradually and in a controlled way, thus preventing eutrophication and pollution of water resources [34] [35]. Nanofertilizers improve crop yield and quality with higher nutrient use efficiencywhile reducing the cost of production and thus, contribute towards agricultural sustainability [36]. Figure 4 illustrates the advantages of nanofertilizers.

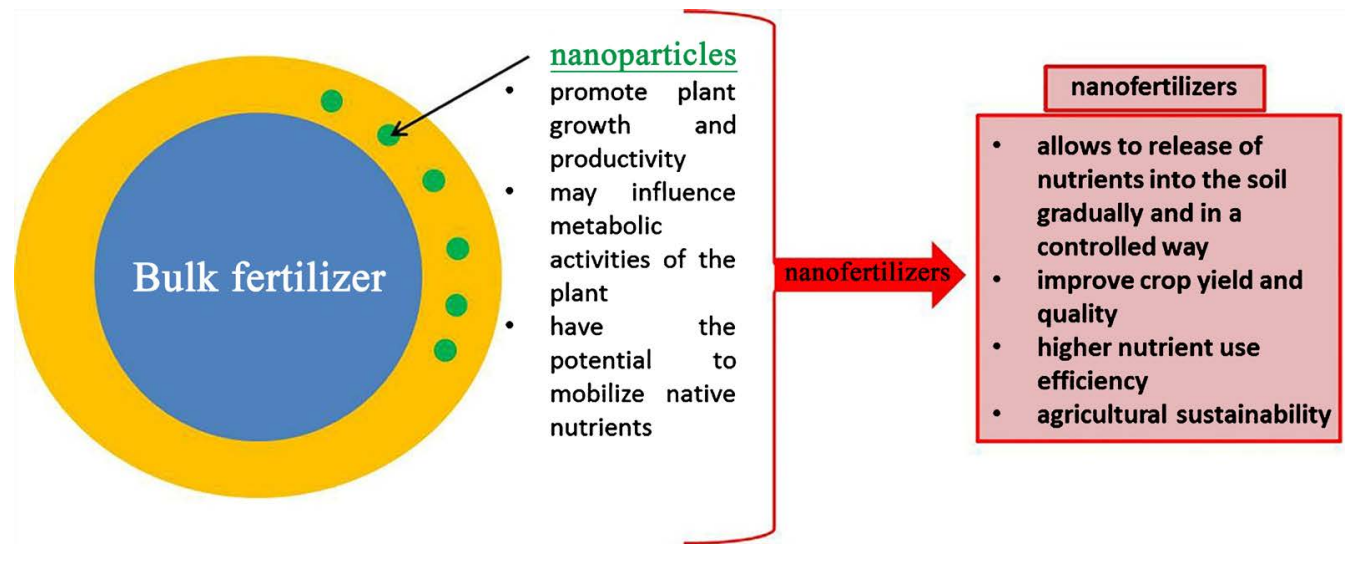

Figure 4. Advantages of nanofertilizers. 
Regarding the development of nanofertilizer technology, the strategy to enter the market should be directed toward the development of high-efficiency products for the major elements $\mathrm{N}, \mathrm{P}, \mathrm{K}, \mathrm{Ca}, \mathrm{Mg}$, and $\mathrm{S}$, which are applied in higher volume and that are currently less efficient and more environmentally impactful. If it is possible to apply less kg per hectare and fewer applications per season with the use of nanofertilizers, the cost of fertilization per unit of fruit yield will be significantly reduced [37].

Compared with conventional fertilizers, the nanofertilizers lower the rate of nutrient release and, on the other hand, increase their stability by aggregation or adsorption but without causing changes in chemical speciation due to $\mathrm{pH}$-dependent phenomena, redox potential, and availability of ligands in the soil [38].

Examples of the aforementioned are 1) the use of nano rock phosphate that increases the bioavailability of $\mathrm{P}$ for plants, since it prevents the fixation of $\mathrm{P}$ by $\mathrm{Fe}, \mathrm{Ca}$, or silicic acid, and 2) the application of modified zeolites with high internal surface for ion exchange for the regulation of $\mathrm{N}, \mathrm{P}$, and $\mathrm{K}$ for plants [39].

Application of phosphatic nanofertilizers has also been linked to an increased growth rate (by $32 \%$ ) and seed yield (by $20 \%$ ) of soybean (Glycine max L.) as compared to those treated with conventional fertilizer [40].

$\mathrm{SiO}_{2}$ and $\mathrm{TiO}_{2}$ nanoparticles increased the activity of nitrate reductase in soybeans and intensified plant absorption capacity, making its use of water and fertilizer more efficient [41].

Furthermore, nanofertilizers may also be used for enhancing abiotic stress tolerance and used in combination with microorganisms (the so-called nanobiofertilizers) to provide great additional benefits. In the case of fertilizer delivery, several investigations confirmed that the application of nano-silicon dioxide with biofertilizer was useful to increase the crop yield [42].

Shebl et al. [43] have synthesized zinc, manganese, and iron nanooxides via a green chemistry technique using a microwave-assisted hydrothermal method with average particle size around $20-60 \mathrm{~nm}$ and small surface areas and applied as a foliar nanofertilizer on squash plants. The obtained results showed that the spraying of manganese oxide nanoparticles on the plants led to the best vegetative growth characteristics, also, the characteristics of the fruits, yield, and the content of photosynthetic pigments. On the contrary, the content of organic matter, protein, lipids, and energy gave the highest value in squash fruits that have been sprayed with iron oxide nanoparticles.

Iron and manganese nanoparticles (NPs) were biosynthesized through a simple and rapid method using bacteria supernatant containing auxin complex (indole-3-acetic, IAA) and evaluated as plant nanofertilizer. The synthesized NPs showed to be suitable as micronutrient fertilizers for crop production. Among them, bimetallic $\mathrm{MnOx} / \mathrm{FeOx}$ NPs from bacterial supernatant showed the best result on plant growth, especially ingermination rates, root growth and fresh weight in maize plantlets indicating that these can be used as micronutrient nanofertilizer [44]. 
Foliar application of NPK nanofertilizers at a 50\% rate in potato production increase production, profit, and quality compared to soil applications. The results in this study show that using lower rates of nanofertilizers as foliar application proved to be an eco-friendly environmental and economic alternative to recommended rates of chemical fertilizers with a significant increase in potato productivity and quality [45].

Abdel-Aziz and co-workers [46] investigated the possible effects of using two engineered nanomaterials nanochitosan (Cs) or carbon nanotubes (CNTs) either alone or loaded with NPK as fertilizers on French bean plants. They found that foliar application improves the growth, yield, and antioxidant system of plants and biochemical content of yielded seeds than seed priming. Moreover, foliar treatment shortened the days to harvest without reducing yield by $37.5 \%$ ( 80 days) as compared with control and seed priming treatment (110 days). Of interest, Cs nanoparticles appeared to improve growth and yield parameters more than CNTs infoliar application treatment. They recommend the use of nanofertilizers as foliar applications.

\section{Impact of Nanopesticides and Nanofertilizers on the Environment}

In particular, the extensive release of nanomaterials into the environment and the food chain may pose a risk to human health [47]. The superficial area of nanoparticles and other physicochemical properties may greatly influence their transformation and bioavailability during spreading into the environment. However, there are still no fully comprehensive systems to establish the assessments for potential effects of pollution between toxicity and nanoparticles in the environment [48]. Although nanotechnology provides numerous benefits, the researchers and experts are worried about the unsafe disposal of various nanoparticles (NPs) in massive amounts (several hundred tons) every year. The recent normative documents recommend that the presence of NPs could be detected in a number of controlled objects (atmospheric air, water objects, soils, hydrobionts, algae, fungi, tissues of land plants, tissues of land animals) [49]. Until now, however, the potential negative impacts of NPs on human health have been rather speculative and uncorroborated [50] [51]. The current level of knowledge on the ecotoxicological effects of nanopesticides is scarce, especially in regard to the fate and behavior of such formulations in the environment [52].

One of the key drivers for the application of nanotechnology is a reduction in the amount of pesticide needed to assure crop protection, which may be achieved by several ways such as by improved apparent solubility, controlled release, targeted delivery, enhanced bioavailability, increased leaf adhesion [53]. Studies [54] [55] reported similar toxicity or increased pesticidal toxicity [56] [57] or similar toxicity at lower concentrations [58] [59] as compared to the conventional to nanopesticide formulations. Studies demonstrate that nanoformulations can slow down the release [60] [61]. Nanoformulations can allow a 
better targeting of the pest. Nanoformulations can protect from various degradation processes including photolysis [62] [63] [64] [65] [66], hydrolysis [67], or degradation in soil [68] [69] [70].

Poor use efficiency of current fertilizers is a major issue. For instance, nitrogen fertilizer, up to $50 \%$ of the nitrogen applied is lost by volatilization and another $5 \%-10 \%$ by leaching [71]. Loss of fertilizers has severe environmental consequences such as eutrophication [71] [72]. Nanotechnology is applied in the sector of plant nutrition with the aim of increasing the use efficiency of current fertilizers, either by improving the delivery of poorly bioavailable elements (for example, phosphorus, zinc) and/or by limiting losses of mobile nutrients to the surrounding environment (for example, nitrate) [73]. The use of alternative growth promoters such as $\mathrm{TiO}_{2}[74]$ or carbon nanotubes [75] is also being explored. Depending on the role of the nanomaterials, and the nutrients in use, nanofertilizers can be separated into three different categories: 1) nanomaterials made of macronutrients, 2) nanomaterials made of micronutrients, and 3) nanomaterials acting as carriers for macronutrients.

The first two categories comprise nanomaterials as nutrient themselves, whereas they are additives in the third category. Some researchers refer to the first two categories only as nanofertilizers, whereas the third category is termed "nutrient-loaded nanofertilizers" or "nanomaterial-enhanced fertilizers" [46]. In comparisons of efficacy for nanofertilizers and non-nano fertilizers according to germination, plant growth or crop yield and compared with the one obtained with the corresponding conventional fertilizer. The resulting wre the median efficacy gain of nanofertilizers over conventional fertilizers was 19\%, 18\% and 29\% for categories 1, 2 and 3 respectively. For category 2 nanofertilizers, about 20\% exhibited lower efficacy than their corresponding conventional analogues. This is probably caused by the toxicity of several micronutrient elements at higher concentrations (acknowledged and addressed in most of the original papers).

The benefits of nanoagrochemicals are improving the toxicity of pesticides to their target pest by up to $20 \%$ relative to conventional analogues. Also, literature has shown that nanofertilizers may increase crop production by some additional $20 \%$ to $30 \%$ compared with conventional fertilizers, so, the advantage achieving of crop protection and nutrition with reducing the use of agrochemicals by $20 \%$ - $30 \%$ could significantly mitigate environmental contamination. There is currently no study that has evaluated the relative environmental footprint of nanoagrochemicals compared with conventional formulations. Given there is general concern about the potential adverse impact that nanoparticles may elicit in terms of both human and environmental health. More work will thus be necessary to evaluate the new risks and benefits that nanoagrochemicals represent relative to existing products.

Therefore, the requirement for current and future studies is to translate into the way of nanotechnology works (mode of action) for plant protection or nutrition, and the design of more sophisticated products that may help to reduce the 
impact that modern agriculture has on environment and human health, and contribute to global food security. Besides, evaluating of nanoagrochemicals against products currently on the market to avoid unjustified expectations or perceived fears associated with the nanotechnology in agriculture. Where, agriculture is in urgent need of innovation to meet the increasing demand in food, while reducing its impact on the environment. It is vital that significant research efforts are invested in the development of novel products that are competitive and have the potential to make tomorrow's agriculture more sustainable. The responsible application of nanotechnologies can hopefully play an important role in reaching this goal.

\section{Conclusions}

From the previous studies, Nanotechnology is a useful tool in modern agriculture to face emerging agricultural and environmental challenges principally related to the needs for increased productivity, sustainability, and security of agriculturally produced foods. The beneficial expectations from applied nanotechnology in agriculture may be helpful to implement delivery systems for agrochemicals, improve plant breeding, reduce the impact of modern agriculture on the environment and input costs while improving the quality and quantity of yields. While, emerging concerns of nanotechnology in the agriculture sector is potential toxicological hazards and risks, including release of nanomaterials into the environment may occur when they are used as nanofertilizers and nanopesticides.

Besides all the great opportunities of application of nanopesticides and nanofertilizers to allow a controlled release of the active compound and improve plant nutrition and stress tolerance to achieve higher yields, not all nanopesticides and nanomaterials will be equally safe. Although the results of the research indicate all the benefits listed in this paper, however, the current level of knowledge about the ecotoxicological effects of nanopesticides is scarce, and it is necessary to examine the risks of application of nanopesticides and nanofertilizers in more detail. In this context, further biotechnological advances are required for a correct and safe application of nanomaterials in agriculture.

\section{Conflicts of Interest}

The authors declare no conflicts of interest regarding the publication of this paper.

\section{References}

[1] Bratovcic, A. (2020) Nanomaterials in Food Processing and Packaging, Its Toxicity and Food Labeling. Acta Scientific Nutritional Health, 4, 7-13.

[2] Ghormade,V., Deshpande, M.V. and Paknikar, K.M. (2011) Perspectives for Nano-Biotechnology Enabled Protection and Nutrition of Plants. Biotechnology Advances, 29, 792-803. https://doi.org/10.1016/j.biotechadv.2011.06.007

[3] Subramanian, K.S., Manikandan, A., Thirunavukkarasu, M. and Rahale, C.S. (2015) 
Nano-Fertilizers for Balanced Crop Nutrition. In: Rai, M., Ribeiro, C., Mattoso, L. and Duran, N., Eds., Nanotechnologies in Food and Agriculture, Springer International Publishing, Cham, 69-80. https://doi.org/10.1007/978-3-319-14024-7_3

[4] Salama, D.M., Osman, S.A., Abd El-Aziz, M.E., Abd Elwahed, M.S.A. and Shaaban, E.A. (2019) Effect of Zinc Oxide Nanoparticles on the Growth, Genomic DNA, Production and the Quality of Common Dry Bean (Phaseolus vulgaris). Biocatalysis and Agricultural Biotechnology, 18, Article ID: 101083.

https://doi.org/10.1016/j.bcab.2019.101083

[5] Sekhon, B.S. (2014) Nanotechnology in Agri-Food Production: An Overview. Nanotechnology Science and Applications, 7, 31-53. https://doi.org/10.2147/NSA.S39406

[6] Stanley, S. (2013) Biological Nanoparticles and Their Influence on Organisms. Current Opinion Biotechnology, 28, 69-74.

https://doi.org/10.1016/j.copbio.2013.11.014

[7] Dasgupta, N., Ranjan, S., Mundekkad, D., Ramalingam, C., Shanker, R. and Kumar, A. (2015) Nanotechnology in Agro-Food: From Field to Plate. Food Research International, 69, 381-400. https://doi.org/10.1016/j.foodres.2015.01.005

[8] Siddiqui, M.H. and Al-Whaibi, M.H. (2014) Role of $\mathrm{Nano}^{-\mathrm{SiO}_{2}}$ in Germination of Tomato (Lycopersicum esculentum Seeds Mill.). Saudi Journal of Biological Sciences, 21, 13-17. https://doi.org/10.1016/j.sjbs.2013.04.005

[9] Mali, S.C., Raj, S. and Trivedi, R. (2020) Nanotechnology a Novel Approach to Enhance Crop Productivity. Biochemistry and Biophysics Reports, 24, Article ID: 100821. https://doi.org/10.1016/j.bbrep.2020.100821

[10] Research Corridor (2020) Nanopesticide Market Size, Share, Growth, Global Trends, Industry Analysis and Forecast to 2027.

https://www.researchcorridor.com/nanopesticide-market/

[11] Mura, S., Greppi, G., Roggero, P.P., Musu, E., Pittalis, D., Carletti, A., Ghiglieri, G. and Irudayaraj, J. (2015) Functionalized Gold Nanoparticles for the Detection of Nitrates in Water. International Journal of Environmental Science and Technology, 12, 1021-1028. https://doi.org/10.1007/s13762-013-0494-7

[12] Delgadillo-Vargas, O., Garcia-Ruiz, R. and Forero-Alvarez, J. (2016) Fertilising Techniques and Nutrientbalances in the Agriculture Industrialization Transition: The Case of Sugarcane in the Cauca River Valley (Colombia), 1943-2010. Agriculture, Ecosystems \& Environment, 218, 150-162. https://doi.org/10.1016/j.agee.2015.11.003

[13] Ware, G.W. (2000) The Pesticide Book. 5th Edition, Thomson Publications, Fresno.

[14] Bratovcic, A. (2020) Biosynthesis of Green Silver Nanoparticles and Its UV-Vis Characterization. International Journal of Innovative Science, Engineering and Technology, 7, 170-176.

[15] Guilger-Casagrande, M., Germano-Costa, T., Pasquoto-Stigliani, T., Fraceto, L.F. and Lima, R. (2019) Biosynthesis of Silver Nanoparticles Employing Trichoderma harzianum with Enzymatic Stimulation for the Control of Sclerotinia sclerotiorum. Scientific Reports, 9, Article No. 14351. https://doi.org/10.1038/s41598-019-50871-0

[16] Elmer, W., De La Torre-Roche, R., Pagano, L., Majumdar, S., Zuverza-Mena, N., Dimkpa, C., Gardea-Torresdey, J. and White, J.C. (2018) Effect of Metalloid and Metal Oxide Nanoparticles on Fusarium Wilt of Watermelon. Plant Disease, 102, 1394-1401. https://doi.org/10.1094/PDIS-10-17-1621-RE

[17] Shukla, G., Gaurav, S.S. and Singh, A. (2020) Synthesis of Mycogenic Zinc Oxidenanoparticles and Preliminary Determination of Its Efficacy as a Larvicide Againstwhite Grubs (Holotrichia sp.). International Nano Letters, 10, 131-139. 
https://doi.org/10.1007/s40089-020-00302-0

[18] Lakshmeesha, T.R., Murali, M., Ansari, M.A., Udayashankar, A.C., Alzohairy, M.A., Almatroudi A., Alomary, M.N., Asiri, S.M.M., Ashwini, B.S., Kalagatur, N.K., Nayak, C.S. and Niranjana, S.R. (2020) Biofabrication of Zinc Oxidenanoparticles from Melia azedarach and Its Potential in Controlling Soybeanseed-Borne Phytopathogenic Fungi. Saudi Journal of Biological Sciences, 27, 1923-1930.

https://doi.org/10.1016/j.sjbs.2020.06.013

[19] Feng, J., Zhang, Q., Liu, Q., Zhu, Z., McClements, D.J. and Jafari, S.M. (2018) Chapter 12: Application of Nanoemulsions in Formulation of Pesticides. In: Mahdi Jafari, S. and McClements, D.J., Eds., Nanoemulsions. Formulation, Applications, and Characterization, Academic Press, Waltham, 379-413.

https://doi.org/10.1016/B978-0-12-811838-2.00012-6

[20] Bratovcic, A. and Suljagic, S. (2019) Micro- and Nano-Encapsulation in Food Industry. Croatian Journal of Food Science and Technology, 11, 113-121.

https://doi.org/10.17508/CJFST.2019.11.1.17

[21] de Oliveira, J.L., Campos, E.V.R., da Silva, C.M.G., Pasquoto, T., Lima, R. and Fraceto, L.F. (2015) Solid Lipid Nanoparticles Co-Loaded with Simazine and Atrazine: Preparation, Characterization, and Evaluation of Herbicidal Activity. Journal of Agricultural and Food Chemistry, 63, 422-432. https://doi.org/10.1021/jf5059045

[22] Grillo, R., Abhilash, P.C. and Fraceto, L.F. (2016) Nanotechnology Applied to Bio-Encapsulation of Pesticides. Journal of Nanoscience and Nanotechnology, 16, 1231-1234. https://doi.org/10.1166/jnn.2016.12332

[23] Nuruzzaman, M., Rahman, M.M., Liu, Y. and Naidu, R. (2016) Nanoencapsulation, Nano-Guard Forpesticides: A New Window for Safe Application. Journal of Agricultural and Food Chemistry, 64, 1447-1483.

https://doi.org/10.1021/acs.jafc.5b05214

[24] Pestovsky, Y.S. and Martinez-Antonio, A. (2017) The Use of Nanoparticles and Nanoformulations in Agriculture. Journal of Nanoscience and Nanotechnology, 12, 8699-8730. https://doi.org/10.1166/jnn.2017.15041

[25] Sabliov, C., Chen, H. and Yada, R. (2015) Nanotechnology and Functional Foods: Effective Delivery of Bioactive Ingredients. 1st Edition, John Wiley \& Sons, Ltd., USA.

[26] Murphy, K. (2008) Nanotechnology: Agriculture's Next “Industrial” Revolution. Vol. 2008. Financial Partner, Yankee Farm Credit, ACA, Williston, 3-5.

[27] Santangelo, S., Gorrasi, G., Di Lieto, R., De Pasquale, S., Patimo, G., Piperopoulos, E., Lanza, M., Faggio, G., Mauriello, F., Messina, G. and Milone, C. (2011) Polylactide and Carbon Nanotubes/Smectite-Clay Nanocomposites: Preparation, Characterization, Sorptive and Electrical Properties. Applied Clay Science, 53, 188-194. https://doi.org/10.1016/j.clay.2010.12.013

[28] García, M., Forbe, T. and Gonzalez, E. (2010) Potential Applications of Nanotechnology in the Agro-Food Sector. Food Science and Technology, 30, 573-581. https://doi.org/10.1590/S0101-20612010000300002

[29] de Francisco, E.V. and García-Estepa, R.M. (2018) Nanotechnology in the Agrofood Industry. Journal of Food Engineering, 238, 1-11. https://doi.org/10.1016/j.jfoodeng.2018.05.024

[30] Gao, Y., Li, D., Li, D., Xu, P., Mao, K., Zhang, Y., Qin, X., Tang, T., Wan, H., Li, J., Guo, M. and He, S. (2020) Efficacy of an Adhesive Nanopesticide on Insect Pests of Rice in Field Trials. Journal of Asia-Pacific Entomology, 23, 1222-1227. https://doi.org/10.1016/j.aspen.2020.08.013 
[31] Peixoto, S., Henriques, I. and Loureiro, S. (2021) Long-Term Effects of $\mathrm{Cu}(\mathrm{OH})_{2}$ Nanopesticide Exposure on Soil Microbial Communities. Environmental Pollution, 269, Article ID: 116113. https://doi.org/10.1016/j.envpol.2020.116113

[32] Rajiv, P., Chen, X., Li, H., Rehaman, S., Vanathi, P., Abd-Elsalam, K.A. and Li, X. (2020) Chapter 18: Silica-Based Nanosystems: Their Role in Sustainable Agriculture. In: Abd-Elsalam, K.A., Ed., Multifunctional Hybrid Nanomaterials for Sustainable Agri-Food and Ecosystems. Micro and Nano Technologies, Elsevier, Amsterdam, 437-459.

[33] DeRosa, M.C., Monreal, C., Schnitzer, M., Walsh, R., et al. (2010) Nanotechnology in Fertilizers. Nature Nanotechnology, 5, 91.https://doi.org/10.1038/nnano.2010.2

[34] Naderi, M.R. and Abedi, A. (2012) Application of Nanotechnology in Agriculture and Refinement of Environmental Pollutants. Journal of Nanotechnology, 11, 18-26.

[35] Moaveni, P. and Kheiri, T. (2011) $\mathrm{TiO}_{2}$ Nano Particles Affected on Maize (Zea mays L). 2nd International Conference on Agricultural and Animal Science, Maldives, 25-27 November 2011, Vol. 22, IACSIT Press, Singapore, 160-163.

[36] Usman, M., Farooq, M., Wakeel, A., Nawaz, A., Cheema, S.A., ur Rehman, H., Ashraf I. and Sanaullah M. (2020) Nanotechnology in Agriculture: Current Status, Challenges and Future Opportunities. Science of the Total Environment, 721, Article No. 137778. https://doi.org/10.1016/j.scitotenv.2020.137778

[37] Ojeda-Barrios, D.L., Morales, I., Juárez-Maldonado, A., Sandoval-Rangel, A., Fuentes-Lara, L.O. and Benavides-Mendoza, A. (2020) Chapter 35-Importance of Nanofertilizers in Fruit Nutrition. In: Srivastava, A.K. and Hu, C., Eds., Fruit Crops. Diagnosis and Management of Nutrient Constraints, Elsevier, Amsterdam, 497-508. https://doi.org/10.1016/B978-0-12-818732-6.00035-6

[38] Raliya, R., Saharan, V., Dimkpa, C. and Biswas, P. (2018) Nanofertilizer for Precision and Sustainable Agriculture: Current State and Future Perspectives. Journal of Agricultural and Food Chemistry, 66, 6487-6503. https://doi.org/10.1021/acs.jafc.7b02178

[39] Singh, M.D., Chirag, G., Prakash, P.O., Mohan, M.H., Prakasha, G. And Vishwajith. (2017) Nano Fertilizers Is a New Way to Increase Nutrients Use Efficiency in Crop Production. International Journal of Agricultural Science, 9, 3831-3833.

[40] Liu, R. and Lal, R. (2014) Synthetic Apatite Nanoparticles as a Phosphorus Fertilizer for Soybean (Glycine max). Scientific Reports, 4, Article No. 5686. https://doi.org/10.1038/srep05686

[41] Lu, C.M., Zhang, C.Y., Wen, J.Q., Wu, G.R. and Tao, M.X. (2002) Research of the Effect of Nanometer Materials on Germination and Growth Enhancement of Glycine Max and Its Mechanism. Soybean Science, 3, 168-172.

[42] Janmohammadi, M., Amanzadeh, T., Sabaghnia, N. and Ion, V. (2016) Effect of Nano-Silicon Foliar Application on Safflower Growth under Organic and Inorganic Fertilizer Regimes. Botanica, 1, 53-64. https://doi.org/10.1515/botlit-2016-0005

[43] Shebl, A., Hassan, A.A., Salama, D.M., Abd El-Aziz, M.E. and Abd Elwahed, M.S.A (2019) Green Synthesis of Nanofertilizers and Their Application as a Foliar for Cucurbita pepo L. Journal of Nanomaterials, 2019, Article ID: 3476347. https://doi.org/10.1155/2019/3476347

[44] de França Bettencourt, G.M., Degenhardt, J., Zevallos Torres, L.A., de Andrade, Tanobe, V.O. and Soccol, C.R. (2020) Green Biosynthesis of Single and Bimetallic Nanoparticles of Iron and Manganese Using Bacterial Auxin Complex to Act as Plant Bio-Fertilizer. Biocatalysis and Agricultural Biotechnology, 30, Article ID: 101822. https://doi.org/10.1016/j.bcab.2020.101822 
[45] Abd El-Azeim, M.M., Sherif, M.A., Hussien, M.S., Tantawy, I.A.A. and Bashandy, S.O. (2020) Impacts of Nano- and Non-Nanofertilizers on Potato Quality and Productivity. Acta Ecologica Sinica, 40, 388-397. https://doi.org/10.1016/j.chnaes.2019.12.007

[46] Abdel-Aziz, H.M.M., Hasaneen, M.N.A. and Omer, A.M. (2019) Impact of Engineered Nanomaterials Either Alone or Loaded with NPK on Growth and Productivity of French Bean Plants: Seed Priming vs Foliar Application. South African Journal of Botany, 125, 102-108. https://doi.org/10.1016/j.sajb.2019.07.005

[47] Zulfiqar, F., Navarro, M., Ashraf, M., Akram, N.A. and Munné-Bosch S. (2019) Nanofertilizer Use for Sustainable Agriculture: Advantages and Limitations. Plant Science, 289, Article ID: 110270. https://doi.org/10.1016/j.plantsci.2019.110270

[48] Bratovcic, A. (2019) Different Applications of Nanomaterials and Their Impact on the Environment. International Journal of Material Science and Engineering, 5, 1-7. https://doi.org/10.14445/23948884/IJMSE-V5I1P101

[49] Rajput, V., Minkina, T., Mazarji, M., Shende, S., Sushkova, S., Mandzhieva, S., Burachevskaya, M., Chaplygin, V., Singh, A. and Jatav, H. (2020) Accumulation of Nanoparticles in the Soil-Plant Systems and Their Effects on Human Health. Annals of Agricultural Sciences, 65, 137-143. https://doi.org/10.1016/j.aoas.2020.08.001

[50] Baranowska-Wojcik, E, Szwajgier, D., Oleszczuk, P. and Winiarska-Mieczan, A. (2020) Effects of Titanium Dioxide Nanoparticles Exposure on Human Health-A Review. Biological Trace Element Research, 193,118-129. https://doi.org/10.1007/s12011-019-01706-6

[51] Staron, A., Dlugosz, O., Pulit-Prociak, J. and Banach, M. (2020) Analysis of the Exposure of Organismsto the Action of Nanomaterials. Materials, 13, 349.

https://doi.org/10.3390/ma13020349

[52] Grillo, R., Fraceto, L.F., Amorim, M.J.B., Scott-Fordsmand, J.J., Schoonjans, R. and Chaudhry Q. (2021) Ecotoxicological and Regulatory Aspects of Environmental Sustainability of Nanopesticides. Journal of Hazardous Material, 404, Article ID: 124148. https://doi.org/10.1016/j.jhazmat.2020.124148

[53] Kah, M., Beulke, S., Tiede, K. and Hofmann, T. (2013) Nanopesticides: State of Knowledge, Environmental Fate, and Exposure Modeling. Critical Reviews in Environmental Science and Technology, 43, 1823-1867. https://doi.org/10.1080/10643389.2012.671750

[54] de Oliveira, J.L., Campos, E.V.R., da Silva, C.M.G., Pasquoto, T., Lima, R. and Fraceto, L.F. (2015) Solid Lipid Nanoparticles Co-Loaded with Simazine and Atrazine: Preparation, Characterization, and Evaluation of Herbicidal Activity. Journal of Agricultural and Food Chemistry, 63, 422-432. https://doi.org/10.1021/jf5059045

[55] Grillo, R., Pereira, A.E., Nishisaka, C.S., de Lima, R., Oehlke, K., Greiner, R. and Fraceto, L.F. (2014) Chitosan/Tripolyphosphate Nanoparticles Loaded with Paraquat Herbicide: An Environmentally Safer Alternative for Weed Control. Journal of Hazardous Materials, 278, 163-171. https://doi.org/10.1016/j.jhazmat.2014.05.079

[56] Anjali, C.H., Sudheer, Khan, S., Margulis-Goshen, K., Magdassi, S., Mukherjee, A. and Chandrasekaran, N. (2010) Formulation of Water-Dispersible Nanopermethrin for Larvicidal Applications. Ecotoxicology and Environmental Safety, 73, 1932-1926. https://doi.org/10.1016/j.ecoenv.2010.08.039

[57] Saini, P., Gopal, M., Kumar, R. and Srivastava, C. (2014) Development of Pyridalyl Nanocapsule Suspension for Efficient Management of Tomato Fruit and Shoot Borer (Helicoverpa armigera). Journal of Environmental Science and Health B, 49, 344-351. https://doi.org/10.1080/03601234.2014.882168 
[58] Kumar, S., Bhanjana, G., Sharma, A., Sidhu, M.C. and Dilbaghi, N. (2014) Synthesis, Characterization and on Field Evaluation of Pesticide Loaded Sodium Alginate Nanoparticles. Carbohydrate Polymers, 101, 1061-1067. https://doi.org/10.1016/j.carbpol.2013.10.025

[59] Memarizadeh, N., Ghadamyari, M., Adeli, M. and Talebi, K. (2014) Preparation, Characterization and Efficiency of Nanoencapsulated Imidacloprid under Laboratory Conditions. Ecotoxicology and Environmental Safety, 107, 77-83. https://doi.org/10.1016/j.ecoenv.2014.05.009

[60] Adak, T., Kumar, J., Shakil, N.A. and Walia, S. (2012) Development of Controlled Release Formulations of Imidacloprid Employing Novel Nano-Ranged Amphiphilic Polymers. Journal of Environmental Science and Health B, 47, 217-225. https://doi.org/10.1080/03601234.2012.634365

[61] Kaushik, P., Shakil, N.A., Kumar, J., Singh, M.K., Singh, M.K. and Yadav, S.K. (2013) Development of Controlled Release Formulations of Thiram Employing Amphiphilic Polymers and Their Bioefficacy Evaluation in Seed Quality Enhancement Studies. Journal of Environmental Science and Health B, 48, 677-685. https://doi.org/10.1080/03601234.2013.778614

[62] Li, Z.Z., Chen, J.F., Liu, F., Liu, A.Q., Wang, Q., Sun, H.Y. and Wen, L.X. (2007) Study of UV-Shielding Properties of Novel Porous Hollow Silica Nanoparticle Carriers for Avermectin. Pest Management Science, 63, 241-246. https://doi.org/10.1002/ps.1301

[63] Sharma, S., Singh, S., Ganguli, A.K. and Shanmugam, V. (2017) Anti-Drift Nano-Stickers Made of Graphene Oxide for Targeted Pesticide Delivery and Crop Pest Control. Carbon, 115, 781-790. https://doi.org/10.1016/j.carbon.2017.01.075

[64] Shang, Q., Shi, Y., Zhang, Y., Zheng, T. and Shi, H. (2012) Pesticide-Conjugated Polyacrylate Nanoparticles: Novel Opportunities for Improving the Photostability of Emamectin Benzoate. Polymers for Advanced Technologies, 24, 137-143. https://doi.org/10.1002/pat.3060

[65] Liang, J., Yu, M., Guo, L., Cui, B., Zhao, X., Sun, C., Wang, Y., Liu, G., Cui, H. and Zeng, Z. (2018) Bioinspired Development of P(St-MAA)-Avermectin Nanoparticles with High Affinity for Foliage to Enhance Folia Retention. Journal of Agricultural and Food Chemistry, 66, 6578-6584. https://doi.org/10.1021/acs.jafc.7b01998

[66] Nguyen, H.M., Hwang, I.C., Park, J.W. and Park, H.J. (2012) Photoprotection for Deltamethrin Using Chitosan-Coated Beeswax Solid Lipid Nanoparticles. Pest Management Science, 68, 1062-1068. https://doi.org/10.1002/ps.3268

[67] Song, S., Liu, X., Jiang, J., Qian, Y., Zhang, N. and Wu Q. (2009) Stability of Triazophos in Self-Nanoemulsifying Pesticide Delivery System. Colloids and Surfaces A: Physicochemical and Engineering Aspects, 350, 57-62. https://doi.org/10.1016/j.colsurfa.2009.08.034

[68] Kah, M., Machinski, P., Koerner, P., Tiede, K., Grillo, R., Fraceto, LF. and Hofmann, T. (2014) Analysing the Fate of Nanopesticides in Soil and the Applicability of Regulatory Protocols Using a Polymer-Based Nanoformulation of Atrazine. Environmental Science and Pollution Research, 21, 11699-11707. https://doi.org/10.1007/s11356-014-2523-6

[69] Kah, M., Weniger, A.K. and Hofmann, T. (2010) Impacts of (Nano)Formulations on the Fate of an Insecticide in Soil and Consequences for Environmental Exposure Assessment. Environmental Science \& Technology, 50, 10960-10967. https://doi.org/10.1021/acs.est.6b02477

[70] Guan, H., Chi, D., Yu, J. and Li, H. (2010) Dynamics of Residues from a Novel 
Nano-Imidacloprid Formulation in Soyabean Fields. Crop Protection, 29, 942-946. https://doi.org/10.1016/j.cropro.2010.04.022

[71] Food and Agricultural Organization of the United Nations (2002) World Agriculture: Towards 2015/2030. http://www.fao.org/3/y3557e/y3557e.pdf

[72] Tilman, D., Cassman, K.G., Matson, P.A., Naylor, R. and Polasky, S. (2002) Agricultural Sustainability and Intensive Production Practices. Nature, 418, 671-677. https://doi.org/10.1038/nature01014

[73] Liu, R. and Lal, R. (2015) Potentials of Engineered Nanoparticles as Fertilizers for Increasing Agronomic Productions. Science of the Total Environment, 514, 131-139. https://doi.org/10.1016/j.scitotenv.2015.01.104

[74] Feizi, H., Kamali, M., Jafari, L. and Rezvani Moghaddam, P. (2013) Phytotoxicity and Stimulatory Impacts of Nanosized and Bulk Titanium dioxide on Fennel (Foeniculum vulgare Mill). Chemosphere, 91, 506-511. https://doi.org/10.1016/j.chemosphere.2012.12.012

[75] Mukherjee, A., Majumdar, S., Servin, A.D., Pagano, L., Dhankher, O.P. and White, J.C. (2016) Carbon Nanomaterials in Agriculture: A Critical Review. Frontiers in Plant Science, 7, 172. https://doi.org/10.3389/fpls.2016.00172 